\title{
Boron isotopes: no 'Arc' in Archean?
}

M.A. SMIT ${ }^{1}$, A. SCHERSTÉN ${ }^{2}$, T. NÆRAA ${ }^{2}$, R.B. EMO ${ }^{1,3}$, E.E. SCHERER ${ }^{4}$, P. SPRUNG ${ }^{5}$, W. BLEEKER ${ }^{6}$, K.

MEZGER ${ }^{7}$, A. MALTESE ${ }^{7}$, Y. CAI ${ }^{8}$, E.T. RASBURY ${ }^{9}$, M.J. WHITEHOUSE $^{10}$

${ }^{1}$ Dept. of Earth, Ocean and Atmospheric Sciences, University of British Columbia, Vancouver, Canada.

${ }^{2}$ Dept. of Geology, Lund University, Lund, Sweden.

${ }^{3}$ Dept. of Earth, Environmental and Biological Sciences, Queensland University of Technology, Australia.

${ }^{4}$ Institut für Mineralogie, Westfälische Wilhelms-Universität, Münster, Germany.

${ }^{5}$ Paul Scherrer Institut, Villigen, Switzerland.

${ }^{6}$ Geological Survey of Canada, Ottawa, Canada.

${ }^{7}$ Institut für Geologie, Baltzerstrasse 1+3, CH-3012 Bern, Switzerland.

${ }^{8}$ Lamont-Doherty Earth Observatory, Columbia University, Palisades, USA.

${ }^{9}$ Dept. of Geosciences, Stony Brook University, Stony Brook, USA.

${ }^{10}$ Dept. of Geosciences, Swedish Museum of Natural History, Stockholm, Sweden.

The continental crust grew and matured compositionally during the Paleo- to Neoarchean through the addition of juvenile tonalite-trondhjemite-granodiorite (TTG) crust. This change has been linked to the start of global plate tectonics, following the general interpretation that TTGs represent ancient analogs of arc magmas. However, partial melting of deep-residing mafic reservoirs, e.g., during density-driven crustal overturning, delamination, or plume activity, would likewise produce TTGs without requiring active-margin processes. Boron analysis could allow discriminating between these models and, so, provide new insight into the formation and petrogenetic setting of Archean juvenile crust.

We analyzed B concentrations and isotope compositions in 3.8-2.8 Ga TTGs from different Archean terranes. Low $\delta^{11} \mathrm{~B}$ values (down to $-16 \%$ ) and $\mathrm{B}$ concentrations (1-3 ppm) of the TTGs, and the correlation of these parameters with $\mathrm{Zr} / \mathrm{Hf}$, indicate differentiation from a common B-poor mafic source that did not undergo addition of B from seawater or seawater-altered rocks. The TTGs thus do not resemble magmatic rocks from active margins, which clearly reflect such $\mathrm{B}$ addition to their source. The B- and ${ }^{11} \mathrm{~B}$-poor nature of TTGs indicates that modern-style subduction may not have been a dominant process in the formation of juvenile continental crust before $2.8 \mathrm{Ga}$. 